\title{
Film Coated Tablet Dosage Form
}

National Cancer Institute

\section{Source}

National Cancer Institute. Film Coated Tablet Dosage Form. NCI Thesaurus. Code C42931.

A tablet covered with a thin layer of water soluble or insoluble polymer. 